\title{
Development of breath test for pneumoconiosis: a case-control study
}

Hsiao-Yu Yang ${ }^{1,2,3^{*}}$ D, Ruei-Hao Shie ${ }^{4}$, Che-Jui Chang ${ }^{1}$ and Pau-Chung Chen ${ }^{1,2,3,5}$

\begin{abstract}
Background: Lipid peroxidation plays an important role in the pathogenesis of pneumoconiosis. Volatile organic compounds (VOCs) generated from lipid peroxidation might be used to detect pneumoconiosis. The objective of this study was to develop a breath test for pneumoconiosis.

Methods: A case-control study was designed. Breath and ambient air were analysed by gas chromatography/mass spectrometry. After blank correction to prevent contamination from ambient air, we used canonical discriminant analysis (CDA) to assess the discrimination accuracy and principal component analysis (PCA) to generate a prediction score. The prediction accuracy was calculated and validated using the International Classification of Radiographs of the Pneumoconiosis criteria combined with an abnormal pulmonary function test as a reference standard. We generated a receiver operator characteristic $(\mathrm{ROC})$ curve and calculated the area under the ROC curve (AUC) to estimate the screening accuracy of the breath test.

Results: We enrolled 200 stone workers. After excluding 5 subjects with asthma and 16 subjects who took steroids or nonsteroidal anti-inflammatory drugs, a total of 179 subjects were used in the final analyses, which included 25 cases and 154 controls. By CDA, 88.8\% of subjects were correctly discriminated by their exposure status and the presence of pneumoconiosis. After excluding the VOCs of automobile exhaust and cigarette smoking, pentane and C5-C7 methylated alkanes constituted the major VOCs in the breath of persons with pneumoconiosis. Using the prediction score generated from PCA, the ROC-AUC was $0.88(95 \% \mathrm{Cl}=0.80-0.95)$, and the mean ROC-AUC of 5 -fold cross-validation was 0.90 . The breath test had good accuracy for pneumoconiosis diagnosis.
\end{abstract}

Conclusion: The analysis of breath VOCs has potential in the screening of pneumoconiosis for its non-invasiveness and high accuracy. We suggest that a multi-centre study is warranted and that all procedures must be standardized before clinical application.

Keywords: Breath test, Volatile organic compounds, Lipid peroxidation, Pneumoconiosis, Breathomics

\section{Background}

Pneumoconiosis is an important occupational lung disease that primarily consists of silicosis and asbestosis. Silicosis results from inhaling silica, which is a common component of rock and sand. Stone carvers, ceramic workers, quarry workers, miners, tunnel drillers, sand blasting workers, sand casting workers, and construction or demolition workers are at high risk for inhaling silica at work [1]. Silicosis in miners has shown a resurgence in recent years [2].

\footnotetext{
* Correspondence: hyang@ntu.edu.tw

${ }^{1}$ Institute of Occupational Medicine and Industrial Hygiene, National Taiwan University College of Public Health, No. 17 Xuzhou Road, Taipei 10055, Taiwan ${ }^{2}$ Department of Public Health, National Taiwan University College of Public Health, Taipei, Taiwan

Full list of author information is available at the end of the article
}

Asbestosis results from inhaling asbestos fibres that cause diffuse interstitial pulmonary fibrosis. The high-risk population includes shipyard workers, construction workers, asbestos textile workers, manufacturing brake lining workers, and asbestos miners or millers [1]. Although asbestos has been gradually banned in many countries, mortality due to asbestos exposure continues to increase in many developed countries. However, the diagnosis of early-stage pneumoconiosis is difficult in clinical practice [3]. The development of new diagnostic methods for pneumoconiosis is warranted.

Lipid peroxidation plays an important role in the pathological mechanisms of pneumoconiosis. When dust particles are inhaled and reach the alveolar space, the 
particles are phagocytosed by alveolar macrophages, where they induce the production of reactive oxygen species (ROS) and associated lipid peroxidation [4, 5]. Animal studies found that some volatile organic compounds (VOCs), such as pentane, are associated with lipid peroxidation [6]. We hypothesized that VOCs generated from lipid peroxidation could be used to detect pneumoconiosis. The objective of the study was to develop a breath test for pneumoconiosis by analysing exhaled VOCs.

\section{Methods}

\section{Study subjects}

We conducted a case-control study and recruited participants from stone workers in Hualien between March 2013 and July 2014. These stone workers processed jade artefacts, building materials, decorations, sculptures, vases, or urns and were exposed to a mixed dust environment. Our previous study found that these stone workers had an increased risk of pneumoconiosis [7].

\section{Occupational and medical histories}

We obtained information on occupational history, sociodemographic indicators, smoking habits, and clinical history through a face-to-face interview using a validated questionnaire. The questionnaire was developed based on filed surveys that were conducted by occupational physicians and industrial hygienists, and it was pretested using senior stone workers in Hualien to correct any ambiguous wording. Cigarette smoking history was obtained, including the age at which smoking began, the age at which smoking ceased, and the average number of cigarettes smoked per day. A physician used a semistructured questionnaire to review the subject's medical history. The ATS-DLD-78-A questionnaire was used to obtain information on the subject's symptoms of lung disease and their personal and family history of lung disease [8]. Disease was diagnosed by medical doctors and confirmed using the subject's hospital and national health insurance records to rule out interstitial lung diseases caused by drugs, scleroderma, systemic lupus erythaematosus, rheumatoid arthritis, or any other autoimmune diseases $[9,10]$.

\section{Medical examinations}

We arranged health examinations for all study subjects in a medical centre of Hualien. The medical examinations included physical examination, chest $\mathrm{x}$-ray, pulmonary function test (PFT), fractional exhaled nitric oxide (FeNO) test, complete blood count (CBC), blood urine nitrogen (BUN), creatinine, fasting sugar, aspartate aminotransferase (AST), alanine aminotransferase (ALT), and urinary analyses. Chest X-rays were read by two physicians who were blind (masked) to the results of the other tests and clinical information. The profusion of pulmonary fibrosis in chest X-rays was graded in accordance with the International Labour Office (ILO)/International Classification of Radiographs of the Pneumoconioses (ICRP). The ILO Standard Digital Images (ILO 2011-D) were used to determine the profusion of pulmonary fibrosis, and a profusion score greater than or equal to $1 / 0$ was defined as parenchymal abnormalities consistent with pneumoconiosis. We performed a standard PFT to measure forced vital capacity (FVC), forced expiratory volume in 1 second (FEV1), and forced expiratory flow between 25 and $75 \%$ of FVC (FEF25-75). An abnormal pulmonary function test was defined as FVC less than $80 \%$ of predicted value or FEV1/FVC less than $70 \%$. PFT was performed by welltrained technicians. The measurement of FeNO followed the ARS/ERS recommendation [11]. Blood and urine samples were collected after overnight fasting.

\section{Case ascertainment}

This study applied the ILO/ICRP criteria to diagnose pneumoconiosis. A case of pneumoconiosis was determined as having parenchymal abnormalities consistent with pneumoconiosis combined with abnormal pulmonary function test.

\section{Exclusion criteria}

Diabetes mellitus [12], uraemia [13], asthma [14], chronic obstructive pulmonary disease (COPD) [15], pulmonary tuberculosis [16], cancers [17], infectious diseases [18], and the use of anti-inflammatory drugs might influence VOCs. We excluded subjects from the final analysis if they had an acute infection (defined as a white blood cell count greater than $\left.10.0 \times 10^{3} / \mu \mathrm{L}\right)$, poorly controlled diabetes mellitus (defined as a medical history of diabetes combined with a fasting blood glucose level greater than $250 \mathrm{mg} / \mathrm{dL}$ ), uraemia (defined as an estimated glomerular filtration rate of less than $60 \mathrm{~mL} / \mathrm{min}$ with uremic symptoms or a medical history of dialysis), COPD diagnosed by a physician, asthma (a medical history of asthma with a mean FeNO value greater than $50 \mathrm{ppb}$ based on three repeated measurements, indicating significant airway inflammation [11] on the examination day), or were using steroids or nonsteroidal anti-inflammatory drugs (NSAIDs) on the examination day.

\section{Collection and analysis of breath air}

This study applied single-breath sampling with a single expiratory capacity manoeuvre [19]. We used 1-1 Entech Bottle-Vac canisters (Entech Instruments Inc., Simi Valley, CA, USA) to sample breath and background ambient air. Standardized preparation, sampling, and analytical procedures for the breath test included the following steps. (A) Step 1: before sampling, all canisters were cleaned in a 
qualified laboratory to prevent contamination. (B) Step 2: initial vacuum pressure was measured using a Micro-QT Valve Vacuum Check Gauge; a negative pressure of -30 $\mathrm{Hg}$ is required. (C) Step 3: collect 1 litre of background ambient air. (D) Step 4: collect 1 litre of breath sample. (E) Step 5: use the robotic headspace autosampler to introduce the samples into the column. (F) Step 6: pre-concentration. Finally, (G) Step 7: perform gas chromatograph-mass spectrometer (GC-MS) analysis. Because some VOCs might be generated from food or bacteria in the oral cavity [20], study subjects refrained from eating for $8 \mathrm{~h}$ and rinsed their mouths with distilled water prior to breath air sampling. All subjects sat in the room for at least $1 \mathrm{~h}$ before the breath samples were collected. The subjects exhaled 1 litre of breath into a disposable mouthpiece connected to a negative pressure canister. One litre of background ambient air was also sampled simultaneously. All canisters were immediately sent to an accredited laboratory for analysis. Gas samples were analysed within $48 \mathrm{~h}$. Samples were analysed using an Entech 7500A Robotic Headspace Autosampler attached to an Entech 7150 Air/Headspace Preconcentrator using active solid-phase microextraction (SPME) (Entech Instruments Inc., Simi Valley, CA, USA) coupled to an Agilent 6890 N GC /5975C MS (Agilent Technologies, Santa Clara, CA, USA). VOCs were analysed qualitatively and quantitatively in accordance with U.S. Environmental Protection Agency Method TO-15 for the analysis of VOCs in air [21]. An internal standard spiking mixture containing bromochloromethane, chlorobenzene- $\mathrm{d}_{5}, 1,4$-difluorobenzene, and bromofluorobenzene at $10 \mathrm{ppmv}$ each in humidified zero air was added to the sample for correction and calibration. The addition of $500 \mu \mathrm{L}$ of this mixture to $500 \mathrm{~mL}$ of the sample resulted in a concentration of 10 ppbv. The internal standard was introduced into the focus trap during the collection time for all calibration, blank, and sample analyses. The volume of internal standard spiking mixture added to each analysis was the same for each run [21]. Internal standard responses and retention times were evaluated immediately after data acquisition. If the retention time for any internal standard changed by more than $20 \mathrm{~s}$ from the mean retention time over the initial calibration range or if the area response for any internal standard changed by more than $40 \%$ between the sample and the most recent valid calibration, the GC-MS system was inspected and corrected. Chromatographic data processing was performed manually by an experienced analyst using Agilent Chemstation Software (Agilent Technologies, Santa Clara, CA, USA). The National Institute of Standards and Technology (NIST) Library was used as the reference library. To increase the validity of measurement, we retained only those compounds with library match scores higher than $90 \%$. Mass spectrum peaks for which proper identification was not possible because of poor library matches and a lack of confirmed retention times were then discarded. We performed standard blank correction to prevent contamination from ambient air; the concentrations of VOCs of ambient air were subtracted from the concentrations of VOCs of breath air for analysis [22, 23].

\section{Statistics}

First, we used canonical discriminant analysis (CDA) and a forward stepwise method to build the discriminant model among (1) dust-exposed stone workers with pneumoconiosis, (2) dust-exposed stone workers without pneumoconiosis, and (3) non-dust-exposed stone workers who were primarily responsible for sales or administrative work and who did not have pneumoconiosis. Using the ILO/ICRP criteria combined with an abnormal pulmonary function test as the golden standard for pneumoconiosis, we calculated the discrimination accuracy of the breath test. We excluded the VOCs of common automobile exhaust and smoking, and we selected VOCs that were higher in the persons with pneumoconiosis who had lung crackles. A dimension reduction method was used to generate the prediction models [24]. By principal component analysis (PCA), we extracted latent components with eigenvalues $>1$ and obtained their factor scores. Linear combinations of these factor scores were used to generate a prediction score [25]. We generated a receiver operator characteristic (ROC) curve and calculated the area under the ROC curve (AUC) to estimate the screening accuracy of the breath test. The accuracy was validated by a 5 -fold cross-validation method to obtain a mean value of model accuracy. The data were randomly divided into 5 groups. For each test, one group was removed from the set and was used as the test set, and the remaining four groups formed the training set. The model was built on the training set and was validated on the test set. We then obtained a mean value of model accuracy [26]. Statistical calculations were performed using the pROC package in $\mathrm{R}$ software [27] and PASW Statistics 16 (The IBM Corporation, Somers, NY, USA).

\section{Results}

A total of 200 subjects were enrolled in the study. After excluding five subjects with a medical history of asthma with FeNO greater than $50 \mathrm{ppb}$ on the examination day and 16 subjects using steroids or taking NSAIDs on the examination day, a total of 179 subjects were included in the final analysis, which included 25 cases and 154 controls. Cases had a higher proportion of males and were older than controls. The proportions of possible exposure to asbestos were higher in cases than controls (Table 1). In discriminant analysis, $88.8 \%$ of the subjects were correctly classified by their exposure and presence of pneumoconiosis (Fig. 1). We identified 195 VOCs by GC-MS. After excluding the VOCs of automobile exhaust and cigarette smoking, the PCA analysis showed 
Table 1 Characteristics of study subjects

\begin{tabular}{lll}
\hline & Cases $(n=25)$ & Controls $(n=154)$ \\
\hline Men, \% & 68.0 & 46.1 \\
Age (yrs.), mean (SD) & $60.0(9.2)$ & $50.3(11.8)$ \\
Duration of stone work (yrs.), mean (SD) & $19.8(14.5)$ & $17.6(13.8)$ \\
BMI (SD) & $25.7(3.6)$ & $25.1(3.9)$ \\
FVC (\% of predicted) (SD) & $74.3(9.5)$ & $93.8(14.3)$ \\
FEV1 (\% of predicted) (SD) & $75.6(9.4)$ & $95.4(14.4)$ \\
FEV1/FVC (\%) (SD) & $83.2(6.8)$ & $84.0(7.7)$ \\
FEF25-75 (\% of predicted) (SD) & $72.9(20.7)$ & $87.9(25.0)$ \\
Cigarette smoking & & $39.0(24.8)$ \\
$\quad$ Pack years, mean (SD) & $39.2(35.6)$ & 66.2 \\
$\quad$ Never smoked, \% ${ }^{\text {a }}$ & 44.0 & 11.0 \\
$\quad$ Former smoker, \% & 16.0 & 22.7 \\
$\quad$ Current smoker, \% & 40.0 & 40.3
\end{tabular}

"Never smoked" means having smoked fewer than 20 packs of cigarettes in a lifetime or less than one cigarette per day for 1 year

b"Passive smoking" means having been exposed to others smoking more than three times per week for more than 6 months

'Occupational exposure to asbestos at ship demolition, asbestos cement, or carving asbestos-contaminated ores including nephrite, serpentine, and talc

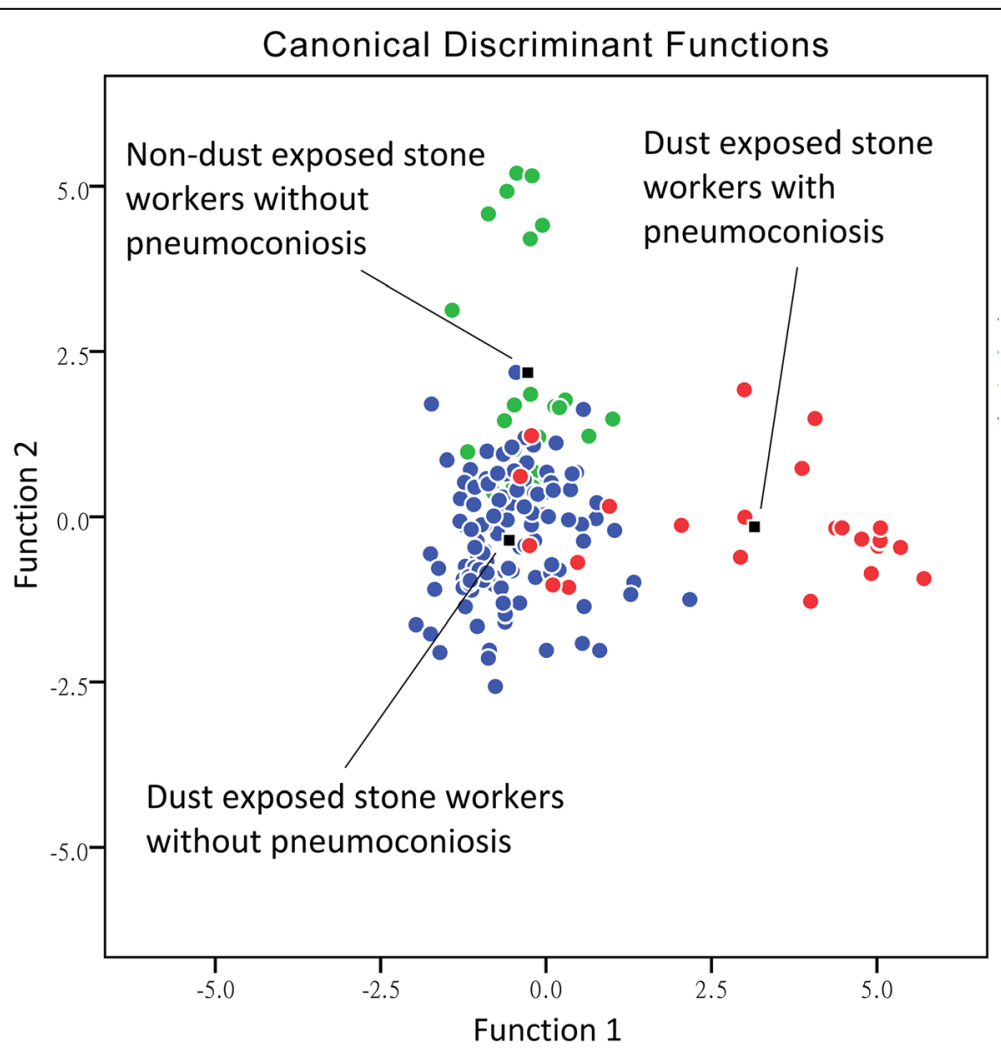

Fig. 1 Classification of subjects by the exposure status and presence of pneumoconiosis. Legend: The subjects were classified into three groups. By canonical discriminant analysis and a forward stepwise method, $88.8 \%$ of the original grouped cases were correctly classified 
that pentane, methylated heptane, and methylated cyclohexane were the major constituents identified in cases of pneumoconiosis who had lung crackle. We generated a predictive score using three factor scores. Using the Youden index to determine the best cut-off point with the largest value of (sensitivity + specificity -1 ) [28], the sensitivity was $100.0 \%$, the specificity was $74.7 \%$, the positive predicted value was $19.2 \%$, and the negative predicted value was $100.0 \%$. The predictive score had good diagnostic accuracy (AUC $=0.88,95 \% \mathrm{CI}=0.80-0.95$ ). The mean AUC of 5 -fold cross-validation was 0.90 (Fig. 2). The concentrations of the VOCs used in the prediction model are summarized in Table 2. A significantly higher concentration of pentane was observed in cases of pneumoconiosis than in healthy controls.

\section{Discussion}

The analysis of VOCs in breath is a novel screening method in respiratory research. Pentane, C5-C7 alkanes, and methylated alkanes constitute a distinct fingerprint in the breath of pneumoconiosis patients. This study showed that exhaled breath might be used in the screening of pneumoconiosis.

This study paid particular attention to methodological issues. We used standard blank correction to eliminate contamination from ambient air. Moreover, we excluded subjects with co-morbidities or the use of medications that might have influenced exhaled VOCs. The composition of body adipose tissues may affect the measurement of lipid metabolite profiles [29]. In this study, the subjects rested for $1 \mathrm{~h}$ before sampling to prevent interference from exercise-induced lipid metabolites [30]. Gas-uptake pharmacokinetic studies in rats have shown the elimination half-life of pentane to be approximately $0.13 \mathrm{~h} \mathrm{[31].} \mathrm{Considering} \mathrm{the} \mathrm{bioaccumulation} \mathrm{of} \mathrm{environ-}$ mental VOCs, all of our study subjects sat for at least $1 \mathrm{~h}$ before breath samples were collected, which allowed exogenous VOCs to be eliminated from breath air.

The significance of this study is its translation of basic breathomics research into clinical application. Breathomics is a developing area of personalized medicine based on the capture, identification, and quantification of VOC patterns in human breath and the utilization of these data as tools in the diagnosis of diseases [32]. The metabolome reflects the interaction between the genome and the environment of an organism and reveals the ultimate response of an organism to genetic alterations, disease, and environmental influences [33]. Of particular interest to metabolomics researchers are small, lowmolecular-weight compounds that serve as substrates and products in various metabolic pathways [34]. In particular, the concentrations of $\mathrm{C} 4-\mathrm{C} 20$ alkanes in the atmosphere and in breath are very low [35]. There is a critical gap between the qualitative and quantitative analytical methods for measuring these small-molecule metabolites. In this study, the analytical methods used were in accordance with the standard U.S. Environmental Protection Agency Method TO-15 for the analysis of trace VOCs in environmental air. We used GC-MS coupled with an air pre-concentrator capable of

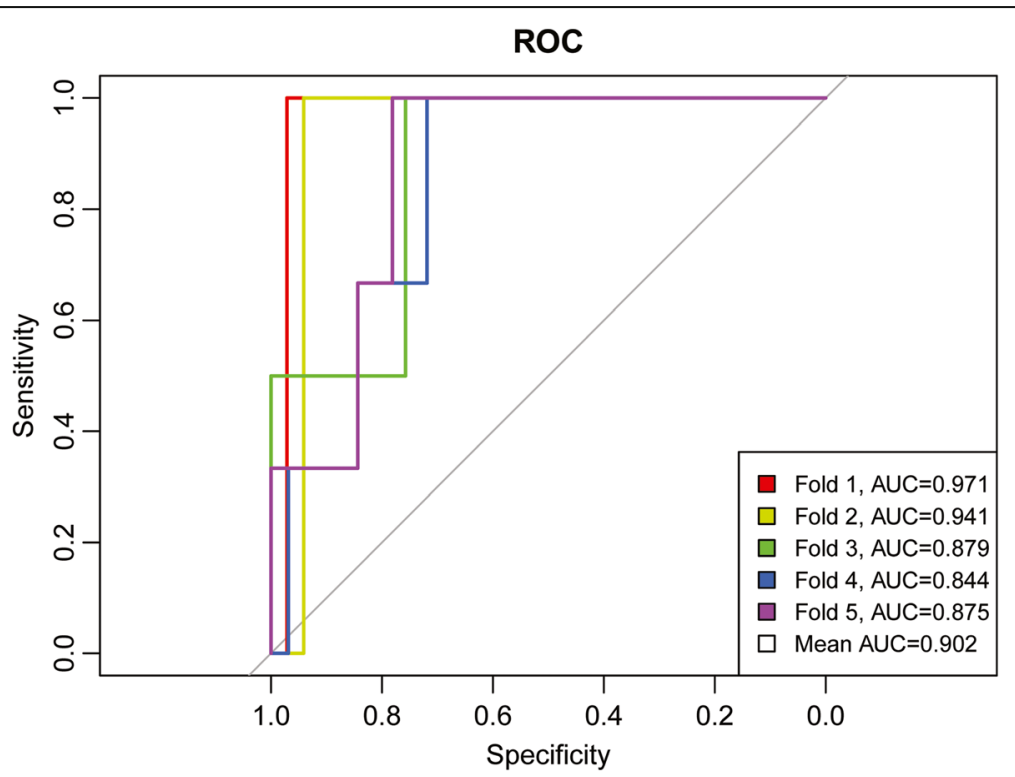

Fig. 2 Receiver operating characteristic curves for pneumoconiosis using 5-fold cross-validation. Legend: The data were randomly divided into 5 groups. For each test, one group was removed from the set and was considered the test set, and the remaining four groups formed the training set. The model was built on the training set and was validated on the test set. The mean area under the curve (AUC) of the model is greater than 0.9 , which suggests high diagnostic accuracy of the breath test 
Table 2 Concentrations of volatile organic compounds in breath samples

\begin{tabular}{|c|c|c|c|c|c|}
\hline \multirow[t]{2}{*}{ Compound } & \multicolumn{2}{|c|}{ Case group } & \multicolumn{2}{|c|}{ Control group } & \multirow[t]{2}{*}{$P$-value ${ }^{a}$} \\
\hline & Mean & Std. Error of Mean & Mean & Std. Error of Mean & \\
\hline Methyl chloride & 12.0 & 5.2 & 5.4 & 1.0 & 0.02 \\
\hline Acetone & 722.0 & 106.8 & 526.9 & 43.6 & 0.01 \\
\hline Pentane & 2.2 & 0.8 & 1.2 & 0.4 & 0.03 \\
\hline Hexane & 0.3 & 0.1 & 0.5 & 0.2 & 0.04 \\
\hline Butanal, 3-methyl- & 0.5 & 0.4 & 0.2 & 0.1 & 0.01 \\
\hline 1,4-Cyclohexadiene, 1-methyl-4-(1-methyl) & 0.4 & 0.3 & 0.2 & 0.2 & 0.02 \\
\hline Phenylethyl alcohol & 13.5 & 13.5 & 0.03 & 0.03 & $<0.01$ \\
\hline Cyclohexane, 1-methylene-3-(1-methylethyl) & 1.2 & 1.1 & 0.4 & 0.3 & $<0.01$ \\
\hline Bicyclo[4.1.0]heptane, 3,7,7-trimethyl- & 41.0 & 27.2 & 9.7 & 4.7 & $<0.01$ \\
\hline
\end{tabular}

${ }^{a}$ One-tailed $P$-value of Wilcoxon signed ranks test

measuring trace VOCs at the sub-ppb level and performed high-throughput measurements to extend the compound ranges from $\mathrm{C} 5$-C12. Because metabolites are fast-moving targets, sample preparation is the most time-consuming and important step in this process. This study used an Entech Bottle-Vac instead of a Tedlar bag for sampling because the internal surface of the Entech Bottle-Vac is similar to that of a GC column, which allows the collected VOCs to remain stable for weeks prior to analysis [36].

The oxidation of fatty acids, also known as lipid peroxidation, is an important process that results from oxidative stress [37]. Lipid bilayers are basic components of physiological cell membranes. Pentane is a metabolite of lipid peroxidation [38]. In vitro studies have shown that the straight-chain aliphatic hydrocarbons of ethane and pentane are generated from the peroxidation of polyunsaturated fatty acids in the lipid bilayers of the cell membrane when cell cultures are exposed to ROS [39]. Methylated hydrocarbons, such as 3-methyltridecane, 3methylundecane, and 5-methylnonane, have been used as markers of lipid peroxidation [40]. In this study, C5C7 alkanes and methylated alkanes constituted the distinctive pattern of VOCs in the breath of pneumoconiosis. The alkanes and methylated alkanes have been used as indicators of lipid peroxidation in some diseases, such as interstitial lung diseases [41], cystic fibrosis [42], chronic obstructive pulmonary disease [15], inflammatory bowel disease [43], and scleroderma [44].

Several limitations of our study should be acknowledged. Cigarette smoking might influence exhaled breath [45]. In this study, we did not exclude current smokers from the final analyses because a high proportion of the workers had a history of smoking and their exclusion would decrease the statistical power. A small sample size and significant differences in terms of age and sex between cases and controls might decrease the validity of this study. This study was based on a case-control study in a medical centre of Hualien. To apply the test to different hospitals, we feel that a multi-centre study is warranted. External validation may validate the robustness of the prediction accuracy with further health-related applications [46]. Because of the limited number of study subjects, this study applied an internal validation method and did not use an independent validation cohort for external validation. The results of this study should be interpreted conservatively. Because this study collected air from the mouth, the exhaled breath might contain both air released from the alveolar-capillary membrane and air in the dead space. The air in the respiratory dead space of the respiratory tract [47], oral cavity, or gastrointestinal tract may influence the VOCs in exhaled air [20]. In this study, all subjects refrained from eating for at least $8 \mathrm{~h}$ to eliminate contamination of the upper airway and oral cavity. To prevent contamination from ambient air, we used a blank correction method to correct the background concentration of VOCs in ambient air and excluded the VOCs of common automobile exhaust and smoking to decrease the influence from environmental contamination in data analyses. Future studies may adopt an inspiratory VOC filter and a mainstream carbon dioxide monitor to collect the alveolar air [48]. The selection of VOCs might be subjective across different studies, and we suggest the procedures must be standardized to ensure reproducibility.

\section{Conclusion}

The metabolites from pathological changes in the alveolarcapillary membrane are directly released into the alveolar space and can be detected in the breath. Lipid peroxidation plays an important role in the pathogenesis of pneumoconiosis. Pentane, C5-C7 alkanes, and methylated alkanes constitute a distinct fingerprint in the breath of persons with pneumoconiosis. VOC analysis in exhaled breath could be used to screen for pneumoconiosis. A multicentre study is warranted, and the procedures must be standardized before clinical application. 


\section{Abbreviations}

AUC: Area under curve; CDA: Canonical discriminant analysis; CVA: Crossvalidated accuracy; FEF25-75: Forced expiratory flow between 25 and $75 \%$ of FVC; FeNO: Fractional exhaled nitric oxide; FEV1: Forced expiratory volume in 1 second; FVC: Forced vital capacity; GC: Gas chromatograph; MS: Mass spectrometer; PCA: Principal component analysis; PFT: Pulmonary function test; ROC: Receiver operator characteristic; ROS: Reactive oxygen species; VOCs: Volatile organic compounds

\section{Acknowledgements}

We thank the Occupational Safety and Health Administration of Labor for administrative support. All authors declare that they have no conflicts of interest to disclose.

\section{Ethics approval and consent to patients}

The study protocol was approved by the Research Ethics Committee (IRB103-31-B), and all subjects provided informed consent.

\section{Funding}

This work was supported by continuous grants from the Ministry of Science and Technology [grant nos. NSC 100-2314-B-320-002-MY3, MOST 104-2314-B002-222-, 105-2314-B-002-065, and MOST 106-2314-B-002-107] and the Occupational Safety and Health Administration of Labor [project nos. 0510101011, 05-10201025, and 05-10301016].

\section{Availability of data and materials}

The datasets analysed during the current study are available from the corresponding author upon reasonable request.

\section{Authors' contributions}

Conception, study design, clinical evaluation, and interpretation of results, $\mathrm{H}$ $\mathrm{H} Y$; analysis of volatile organic compounds in breath, $\mathrm{R} \mathrm{H} \mathrm{S}$; revising important intellectual content and statistical review, P C C; writing the paper, revisions and approval, all authors; statistical analysis, C J C.

\section{Consent for publication}

Not applicable.

\section{Competing interests}

The authors declare that they have no competing interests.

\section{Publisher's Note}

Springer Nature remains neutral with regard to jurisdictional claims in published maps and institutional affiliations.

\begin{abstract}
Author details
'Institute of Occupational Medicine and Industrial Hygiene, National Taiwan University College of Public Health, No. 17 Xuzhou Road, Taipei 10055, Taiwan ${ }^{2}$ Department of Public Health, National Taiwan University College of Public Health, Taipei, Taiwan. ${ }^{3}$ Department of Environmental and Occupational Medicine, National Taiwan University Hospital, Taipei, Taiwan. ${ }^{4}$ Green Energy \& Environmental Research Laboratories, Industrial Technology Research Institute, Hsinchu, Taiwan. ${ }^{5}$ Department of Environmental and Occupational Medicine, National Taiwan University College of Medicine, Taipei, Taiwan.
\end{abstract}

Received: 3 July 2017 Accepted: 6 October 2017

Published online: 17 October 2017

\section{References}

1. LaDou J, editor. Current ocupational \& environmental medicine. 4th ed. New York: McGraw-Hill Company; 1997

2. Cohen RA. Resurgent coal mine dust lung disease: wave of the future or a relic of the past? Occup Environ Med. 2016;73:715-6.

3. Joshi TK, Gupta RK. Asbestos in developing countries: magnitude of risk and its practical implications. Int J Occup Med Environ Health. 2004:17:179-85.

4. Fubini B, Hubbard A. Reactive oxygen species (ROS) and reactive nitrogen species (RNS) generation by silica in inflammation and fibrosis. Free Radic Biol Med. 2003;34:1507-16.

5. Kamp DW, Weitzman SA. The molecular basis of asbestos induced lung injury. Thorax. 1999;54:638-52.
6. Kneepkens CM, Lepage G, Roy CC. The potential of the hydrocarbon breath test as a measure of lipid peroxidation. Free Radic Biol Med. 1994;17:127-60.

7. Yang HY, Shie RH, Chen PC. Pulmonary fibrosis in workers exposed to nonasbestiform tremolite asbestos minerals. Epidemiology. 2013;24:143-9.

8. Ferris BG. Epidemiology standardization project (American Thoracic Society). Am Rev Respir Dis. 1978;118:1-120.

9. Gutsche M, Rosen GD, Swigris JJ. Connective tissue disease-associated interstitial lung disease: a review. Curr Respir Care Rep. 2012;1:224-32.

10. Jee AS, Corte TJ, Wort SJ, Eves ND, Wainwright CE, Piper A. Year in review 2016: interstitial lung disease, pulmonary vascular disease, pulmonary function, paediatric lung disease, cystic fibrosis and sleep. Respirology. 2017; 22:1022-34.

11. Dweik RA, Boggs PB, Erzurum SC, Irvin CG, Leigh MW, Lundberg JO, et al. An official ATS clinical practice guideline: interpretation of exhaled nitric oxide levels (FENO) for clinical applications. Am J Respir Crit Care Med. 2011;184:602-15.

12. Phillip M, Cataneoa RN, Cheema T, Greenberga J. Increased breath biomarkers of oxidative stress in diabetes mellitus. Clin Chim Acta. 2004;344:189-94.

13. Pagonas N, Vautz W, Seifert L, Slodzinski R, Jankowski J, Zidek W, et al. Volatile organic compounds in uremia. PLoS One. 2012;7:e46258.

14. Robroeks CM, van Berkel JJ, Jobsis Q, van Schooten FJ, Dallinga JW, Wouters EF, et al. Exhaled volatile organic compounds predict exacerbations of childhood asthma in a 1-year prospective study. Eur Respir J. 2013:42:98-106.

15. Paredi P, Kharitonov SA, Leak D, Ward S, Cramer D, Barnes PJ. Exhaled ethane, a marker of lipid peroxidation, is elevated in chronic obstructive pulmonary disease. Am J Respir Crit Care Med. 2000;162:369-73.

16. Phillips M, Basa-Dalay V, Bothamley G, Cataneo RN, Lam PK, Natividad MP, et al. Breath biomarkers of active pulmonary tuberculosis. Tuberculosis (Edinb). 2010;90:145-51.

17. Amal H, Leja M, Funka K, Lasina I, Skapars R, Sivins A, et al. Breath testing as potential colorectal cancer screening tool. Int J Cancer. 2016;138:229-36.

18. Sethi S, Nanda R, Chakraborty T. Clinical application of volatile organic compound analysis for detecting infectious diseases. Clin Microbiol Rev. 2013:26:462-75.

19. Horvath I, Barnes PJ, Loukides S, Sterk PJ, Hogman M, Olin AC, et al. A European Respiratory Society technical standard: exhaled biomarkers in lung disease. Eur Respir J. 2017:49:1600965. [https://doi.org/10.1183/13993003. 00965-2016].

20. Wang T, Pysanenko A, Dryahina K, Spanel P, Smith D. Analysis of breath, exhaled via the mouth and nose, and the air in the oral cavity. J Breath Res. 2008;2:037013

21. U.S. Environmental Protection Agency. Compendium method TO-15: determination of volatile organic compounds (VOCs) in air collected in specially prepared canisters and analyzed by gas chromatography/mass spectrometry (GC/MS). In: Compendium of methods for the determination of toxic organic compounds in ambient air. 2nd ed. Cincinnati: United States Environmental Protection Agency; 1999.

22. Phillips M, Cataneo RN, Ditkoff BA, Fisher P, Greenberg J, Gunawardena R, et al. Prediction of breast cancer using volatile biomarkers in the breath. Breast Cancer Res Treat. 2006;99:19-21.

23. Manning CR. Blank correction of air samples. In: Topics in IH chemistry. Assay Tecnology. https://www.assaytech.com/wp-content/uploads/2017/06/ background_blanks.pdf. Accessed 3 Oct 2017.

24. Broadhurst DI, Kell DB. Statistical strategies for avoiding false discoveries in metabolomics and related experiments in metabolomics and related experiments. Metabolomics. 2006;2:171-96.

25. DiStefano C, Zhu M, Mîndrilă D. Understanding and using factor scores: considerations for the applied researcher. Pract Assessment Res Eval. 2009;14:1-11.

26. Jung Y, Hu J. A K-fold averaging cross-validation procedure. J Nonparametr Stat. 2015;27:167-79.

27. Robin X, Turck N, Hainard A, Tiberti N, Lisacek F, Sanchez JC, et al. pROC: an open-source package for $\mathrm{R}$ and $\mathrm{S}+$ to analyze and compare ROC curves. BMC Bioinformatics. 2011:12:77.

28. Hajian-Tilaki K. Receiver Operating Characteristic (ROC) curve analysis for medical diagnostic test evaluation. Caspian J Intern Med. 2013:4:627-35.

29. Wurtz P, Wang Q, Kangas AJ, Richmond RC, Skarp J, Tiainen M, et al. Metabolic signatures of adiposity in young adults: Mendelian randomization analysis and effects of weight change. PLoS Med. 2014;11:e1001765. 
30. Leaf DA, Kleinman MT, Hamilton M, Barstow TJ. The effect of exercise intensity on lipid peroxidation. Med Sci Sports Exerc. 1997;29:1036-9.

31. Browning E, Snyder R. Ethel Browning's toxicity and metabolism of industrial solvents, Vol. 1: hydrocarbons. 2nd ed. Amsterdam: Elsevier; 1987.

32. Rattray NJ, Hamrang Z, Trivedi DK, Goodacre R, Fowler SJ. Taking your breath away: metabolomics breathes life in to personalized medicine. Trends Biotechnol. 2014;32:538-48.

33. Dettmer K, Hammock BD. Metabolomics-a new exciting field within the "omics" sciences. Environ Health Perspect. 2004;112:A396-7.

34. Buszewski B, Kesy M, Ligor T, Amann A. Human exhaled air analytics: biomarkers of diseases. Biomed Chromatogr. 2007;21:553-66.

35. Takahiro M, Takaharu K. Inadequacy of theoretical basis of breath methylated alkane contour for assessing oxidative stress. Clin Chim Acta. 2003;333:91

36. LeBouf RF, Casteel C, Rossner A. Evaluation of an air sampling technique for assessing low-level volatile organic compounds in indoor environments. J Air Waste Manag Assoc. 2010;60:156-62.

37. Halliwell B, Chirico S. Lipid peroxidation: its mechanism, measurement, and significance. Am J Clin Nutr. 1993;57:715S-24S.

38. Chapman EA, Thomas PS, Yates DH. Breath analysis in asbestos-related disorders: a review of the literature and potential future applications. Breath Res. 2010:4:034001.

39. Pitkanen OM, Hallman M, Andersson SM. Determination of ethane and pentane in free oxygen radical-induced lipid peroxidation. Lipids. 1989;24: 157-9.

40. Phillips M, Cataneo RN, Greenberg J, Grodman R, Gunawardena R, Naidu A. Effect of oxygen on breath markers of oxidative stress. Eur Respir J. 2003;21: 48-51.

41. Kanoh S, Kobayashi H, Motoyoshi K. Exhaled ethane: an in vivo biomarker of lipid peroxidation in interstitial lung diseases. Chest. 2005;128:2387-92.

42. Paredi P, Kharitonov SA, Leak D, Shah PL, Cramer D, Hodson ME, et al. Exhaled ethane is elevated in cystic fibrosis and correlates with carbon monoxide levels and airway obstruction. Am J Respir Crit Care Med. 2000; 161:1247-51.

43. Aghdassi E, Allard JP. Breath alkanes as a marker of oxidative stress in different clinical conditions. Free Radic Biol Med. 2000;28:880-6.

44. Cope KA, Solga SF, Hummers LK, Wigley FM, Diehl AM, Risby TH. Abnormal exhaled ethane concentrations in scleroderma. Biomarkers. 2006;11:70-84.

45. Talhout R, Schulz T, Florek E, van Benthem J, Wester P, Opperhuizen A. Hazardous compounds in tobacco smoke. Int J Environ Res Public Health. 2011;:8613-28.

46. Marco $\mathrm{S}$. The need for external validation in machine olfaction: emphasis on health-related applications. Anal Bioanal Chem. 2014;406:3941-56.

47. de Silva G, Beyette FR Jr. Alveolar air volatile organic compound extractor for clinical breath sampling. Conf Proc IEEE Eng Med Biol Soc. 2014;2014: 5369-72.

48. Schubert JK, Spittler KH, Braun G, Geiger K, Guttmann J. CO(2)-controlled sampling of alveolar gas in mechanically ventilated patients. J Appl Physiol (1985). 2001;90:486-92

\section{Submit your next manuscript to BioMed Central and we will help you at every step:}

- We accept pre-submission inquiries

- Our selector tool helps you to find the most relevant journal

- We provide round the clock customer support

- Convenient online submission

- Thorough peer review

- Inclusion in PubMed and all major indexing services

- Maximum visibility for your research

Submit your manuscript at www biomedcentral.com/submit

) Biomed Central 